\title{
Programa Bolsa Familia y frecuencia escolar: un análisis con el censo demográfico de Brasil de 2010
}

\author{
Ernesto F. L. Amaral \\ RAND Corporation, California (USA) \\ eamaral@rand.org \\ Guilherme Q. Gonçalves \\ Universidade Federal de Minas Gerais (Brasil) \\ gui.quaresma89@gmail.com
}

Recibido: 04-06-2014

Aceptado: 01-10-2015

\section{Resumen}

El Programa Bolsa Familia tiene el objetivo de promover el desarrollo social y el alivio de la pobreza a través de la transferencia directa de ingresos, en combinación con otros programas sociales. Este estudio tiene como objetivo analizar si el programa Bolsa Familia ha tenido una correlación con la escolarización de los niños de las familias perceptoras de las ayudas, que es una de las condiciones del programa. La hipótesis principal es que el niño residente en hogares beneficiados por el programa Bolsa Familia tiene más posibilidades de asistir a la escuela. Los datos del Ministerio de Desarrollo Social y de Lucha contra el Hambre corroboran esta hipótesis. Utilizando los microdatos del Censo de 2010 recogidos por el Instituto Brasileño de Geografía y Estadística (IBGE), en esta investigación se han realizado análisis descriptivos y modelos de regresión logística binaria para diferentes límites de ingreso per cápita del hogar. Estas estimaciones se han llevado a cabo mediante la comparación de los niños que formaban parte de los hogares beneficiarios y los que no eran beneficiarios del programa Bolsa Familia. Se han tenido en cuenta las características del hogar, de la madre y del niño. Los resultados han sido ponderados de acuerdo con el municipio de residencia del niño. En todos los límites de ingresos, los niños beneficiarios del programa eran más propensos a estar escolarizados, en comparación con los niños no beneficiarios del programa Bolsa Familia.

Palabras clave: programas de transferencias condicionadas; bolsa familia; escolarización; pobreza; Brasil. 


\title{
Bolsa Familia Program and School Enrolment: An Analysis of the 2010 Brazilian Demographic Census
}

\begin{abstract}
The Bolsa Família Program goal is to promote social development and poverty reduction, through the direct transfer of conditional cash, in association with other social programs. This study aims to analyze whether Bolsa Família had an association with children's school attendance, which is one of the educational conditions of the program. Our main hypothesis is that children living in households receiving Bolsa Família had greater chances of attending school. Data from the Ministry of Social Development and Combating Famine indicated that children living in households with Bolsa Família had greater school enrolment levels. By using data from the 2010 Demographic Census, collected by the Brazilian Institute of Geography and Statistics (IBGE), some descriptive analyzes and binary logistic regression models were performed for different thresholds of household per capita income. These estimates were made by comparing children who lived in households receiving Bolsa Família to those children not receiving the program. We took into consideration characteristics about the household, mothers, and children. The results were clustered by the municipality of residence of the child. In all income thresholds, children benefiting from Bolsa Família were more likely to be enrolled in school, compared to children not receiving the benefit.
\end{abstract}

Keywords: Conditional Cash Transfer Program; Bolsa Família Program; School Enrolment; Poverty; Brazil.

\section{Referencia normalizada}

Amaral, E.F.L. y G.Q. Gonçalves (2015): "Programa Bolsa Familia y frecuencia escolar: un análisis con el censo demográfico de Brasil de 2010", Política y Sociedad, 52 (3), pp. 741-769.

Sumario: 1. Introducción, 2. Contextualización. 3. Diseño de investigación. 4. Resultados.

5. Consideraciones finales. 6. Bibliografía. 


\section{Introducción}

La desigualdad social es uno de los grandes desafíos de la sociedad brasileña. Los índices de desigualdad en el país se redujeron principalmente después de la aplicación de los programas sociales de transferencias monetarias que surgieron en los años 90 . En 2003, el Gobierno Federal implementó el Programa Bolsa Familia, con el objetivo de unir los programas de transferencia de ingresos existentes y mejorar la focalización de sus acciones. Los beneficiarios deben cumplir ciertas condiciones para recibir la ayuda. Los estudios han generado evidencias de que los programas de transferencias condicionadas de ingresos tienen una asociación significativa con la reducción de la pobreza y la desigualdad de ingresos (Barros et al., 2006, 2007; Behrman, Parker y Todd, 2005; Castro y Modesto, 2010; Hoffman, 2006; Janvry y Sadoulet, 2005; Ravallion y Wodon, 2000; Rawlings y Rubio, 2005; Skoufias, 2005; Skoufias y Parker, 2001; Soares et al., 2006). El Programa Bolsa Familia también muestra una relación clara con la frecuencia de asistencia a la escuela y el rendimiento escolar. Amaral y Monteiro (2013) demostraron que los niños que viven en hogares que reciben el programa Bolsa Familia tuvieron menor tasa de abandono escolar en 2005. Oliveira y Soares (2013) constataron que los beneficiarios del programa Bolsa Familia tienen 11\% menos de probabilidad de repetir el curso en la escuela, en comparación con los estudiantes no beneficiarios pero con el mismo nivel de vulnerabilidad social.

Una de las condiciones del programa Bolsa Familia es que, para percibir las ayudas, las familias deben mandar a la escuela a los niños en edad escolar. El objetivo de este trabajo es verificar que los niños beneficiarios del programa tienen más probabilidades de estar en la escuela que los niños no beneficiarios, como ha sido señalado por Amaral y Monteiro (2013). Si hay una asociación positiva entre ser niño beneficiario del programa y la frecuencia de asistencia escolar, tenemos un indicativo de que la condición del programa se cumple. Esta verificación es muy importante porque el programa Bolsa Familia es un gran programa de transferencias condicionadas del Gobierno brasileño. La hipótesis a comprobar es que los niños que reciben el Bolsa Familia tienen mayor probabilidad de estar regularmente matriculados en la escuela (Neves y Helal, 2007). Para realizar el estudio se utilizan datos del Censo Demográfico de 2010 del Instituto Brasileño de Geografía y Estadística (IBGE). Al contrario de los datos de la Evaluación del Impacto del Programa Bolsa Familia de 2005 y 2009 del Ministerio de Desarrollo Social y de Lucha contra el Hambre (MDS) de Brasil, el Censo Demográfico de 2010 tiene información de todos los municipios brasileños, lo que proporciona una mayor calidad de la investigación (Amaral y Monteiro, 2013). Se utiliza un análisis de estadística descriptiva y modelos de regresión logística binaria para verificar las probabilidades de que los niños de 7 a 14 años de edad frecuenten la escuela en 2010, haciendo una comparación entre los beneficiarios y no beneficiarios del programa Bolsa Familia. El análisis se lleva a cabo con tres límites de renta per cá- 
pita del hogar: máximo de 70,00 Reales, de 140,00 Reales y de 280,00 Reales, teniendo en cuenta las diferentes características del hogar, de la madre, del niño y del cobro del programa Bolsa Familia. El ingreso límite de hasta 140,00 Reales corresponde al valor máximo oficial para que la familia sea elegida como beneficiaria del programa Bolsa Familia en 2010. El límite inferior tiene como objetivo atender la situación de los niños en hogares con situaciones económicas más precarias. El límite superior de ingreso aumenta el tamaño de la muestra analizada, lo que permite verificar el efecto de la recepción del programa sobre la frecuencia escolar en niños de hogares con mejores ingresos (Romero, 2008).

Además de esta introducción, este artículo se organiza en cuatro secciones. En primer lugar, se presenta una contextualización de nuestro estudio, incluyendo la discusión de las transferencias de ingresos, origen y características del programa Bolsa Familia. Se incluye también la presentación de los estudios sobre el impacto de este programa. La sección siguiente presenta la estrategia de investigación adoptada, especificando la base de datos utilizada, las variables analizadas, la hipótesis de investigación y los modelos de regresión estimados. Luego se analizan los principales resultados encontrados. Por último, se presentan las consideraciones finales.

\section{Contextualización}

\subsection{Los programas de transferencia de ingresos en Brasil}

La erradicación de la pobreza y la reducción de la desigualdad social son algunos de los mayores desafíos de la sociedad brasileña. Las diferencias económicas entre las clases más ricas y más pobres están disminuyendo, sobre todo después del comienzo de la ejecución de los programas de transferencia de ingreso en los años 90. Desde entonces, el Gobierno Federal ha aumentado la inversión en programas de transferencias condicionadas. Las políticas de transferencias de ingresos actuales tienen como objetivo una resolución de los problemas sociales y de la pobreza y no sólo la atenuación de estos problemas en el corto plazo, tal como se caracterizaron las políticas compensatorias de las décadas anteriores (Carvalho y Fontes, 2012). Los programas de transferencias monetarias han sido diseñados de acuerdo con la idea de que los beneficiarios son los que determinan la utilización de la ayuda, con la suposición de que estos individuos conocen mejor que nadie su realidad y necesidades más urgentes. Algunos de estos programas llevan en su nombre el destino del beneficio, tal como el Auxílio Gás. En estos casos, las políticas se han configurado con la expectativa de que sea el beneficiario quien pueda obtener la máxima satisfacción de sus necesidades y los de su familia, lo que ha de permitir la reducción de los efectos de su condición de pobreza (Santana, 2007). Los programas Auxílio Gás, Bolsa Alimentação, Bolsa Escola y Cartão Alimen- 
tação fueron implementados por el Gobierno Federal en la década de 2000, como se muestra a continuación.

El programa de transferencia de ingresos Auxílio Gás se destinaba a subvencionar la compra de gas envasado para las familias pobres. Cada dos meses, cada familia recibía el equivalente a 15,00 Reales, sin condición alguna para la familia beneficiaria. En octubre de 2003, el programa Auxílio Gás benefició a más de 9 millones de hogares, mientras que poco más de 1,1 millones de familias estaban en el programa Bolsa Familia. En octubre de 2008, con el constante proceso de trasvase de los beneficiarios para el programa Bolsa Familia, el de Auxílio Gás pasó a beneficiar a un poco más de 230 mil hogares en todo Brasil. Mientras tanto, el programa Bolsa Familia contaba con más de 11 millones de familias asistidas.

El programa Bolsa Alimentação fue creado en 2001 por el Ministerio de la Salud para promover mejores condiciones de salud y nutrición de las mujeres y los niños, centrándose en las mujeres embarazadas, madres en periodo de lactancia, así como niños de seis meses a seis años y once meses de edad en situación de riesgo nutricional. Los beneficiarios pertenecían a familias sin ingresos o que tenían un ingreso mensual de hasta 90,00 Reales per cápita. El valor de la ayuda era de 15,00 Reales por mes por beneficiario con un máximo de tres destinatarios por familia. Al inscribirse en el programa, la familia se comprometía a la realización de una agenda de compromisos de salud, que consistía en acciones básicas como la atención prenatal y la vacunación.

El programa Bolsa Escola creado por el Gobierno Federal en 2001 y consistía en la transferencia de recursos para las familias beneficiarias con la condición de que los niños fuesen a la escuela. Con la ayuda financiera y la condicionalidad de la educación, el objetivo era evitar que el niño trabajase para complementar los ingresos familiares. Específicamente, como condición para la recepción de la prestación, todos los niños entre 6 y 15 años de edad del hogar debían estar matriculados en la escuela primaria, con una frecuencia de asistencia escolar de por lo menos $85 \%$. El ingreso familiar per cápita debía ser inferior a 90,00 Reales. Cada hogar podría tener un máximo de tres niños inscritos en el programa, con el beneficio de 15,00 Reales por niño.

Por ultimo el programa Cartão Alimentação de 2002 (Brasil, 2012a) consistía en la transferencia de ingresos para la compra de alimentos con una tarjeta magnética, destinado a las familias atendidas por el programa Fome Zero. La cantidad asignada a cada familia registrada para recibir la prestación fue de 50,00 Reales. Además de la aplicación de los recursos en la nutrición, el programa requería que las familias beneficiarias que tenían adultos analfabetos asistiesen a cursos de alfabetización y cumpliesen contrapartidas específicas requeridas en cada región. El objetivo final del programa era garantizar la emancipación socioeconómica de la familia. El componente principal del programa fue la promoción de la organización de la familia y de la comunidad mediante la participación de la gente y tenía por objeto el desarrollo de la economía local. 


\subsection{El programa Bolsa Familia}

En 2003, durante el gobierno del presidente Luiz Inácio Lula da Silva, el programa Bolsa Familia fue implementado con el objetivo de unirlo a los programas de transferencia de ingresos existentes hasta entonces (Auxílio Gás, Bolsa Alimentação, Bolsa Escola y Cartão Alimentação), Iba dirigido a aumentar el foco de las acciones de estas políticas (Brasil, 2012b). El Bolsa Familia utiliza el registro unificado del Cadastro Único como una forma de identificación y selección de los beneficiarios. El registro es una base de datos creada en 2001 por el Gobierno Federal, que recopila información acerca de las familias de bajos ingresos en el país. La creación del registro permitió reunir información de las familias atendidas por los programas federales existentes, así como mejorar la identificación de las familias que habrían de ser el foco del programa. En 2013, aproximadamente 13 millones de hogares fueron beneficiados por el Bolsa Familia en todo el país. La cuantía de las ayudas abonadas por el programa varía según las características de cada familia, teniendo en cuenta el ingreso familiar per cápita, el número de niños y adolescentes hasta 17 años, las mujeres embarazadas, las madres en periodo de lactancia y los componentes de la familia. En contrapartida las familias asumen unas obligaciones en las áreas de la educación y la salud: (1) garantizar una frecuencia de asistencia escolar mínima del $85 \%$ de los niños entre 6 y 15 años; (2) facilitar información acerca de la vacunación, crecimiento y desarrollo de los niños hasta los 7 años; (3) obtener supervisión en el parto y posparto; y (4) tener vigilancia nutricional del Sistema de Vigilância Alimentar e Nutricional (SISVAN).

El programa Bolsa Familia tiene tres elementos principales: (1) la transferencia de ingresos para promover el alivio inmediato de la pobreza; (2) fijar las condiciones para romper el ciclo intergeneracional de la pobreza; y (3) programas complementarios que son acciones coordinadas de los gobiernos federal, estatal y municipal, así como de la sociedad civil (Rios-Neto, 2010). Las condiciones que establece el programa refuerzan el acceso a los derechos sociales básicos como la educación, la salud y la atención social. Los programas complementarios tienen como objetivo el desarrollo de las familias para garantizar que los beneficiarios sean capaces de superar la situación de vulnerabilidad. A corto plazo, el programa Bolsa Familia busca reducir el nivel de pobreza entre las familias elegidas. A largo plazo, el programa busca potenciar la inversión en el capital humano de las familias, luchando contra la transmisión intergeneracional de la vulnerabilidad y la pobreza. La vinculación de las transferencias condicionadas de ingresos a escolarización de los niños se justifica en que, debido a los bajos ingresos familiares, mantener a los niños escolarizados tendría altos costos para las familias beneficiarias. Más específicamente la explicación es que, si no recibieran la ayuda y dada su precaria situación económica, estas familias tendrían la necesidad de que los niños tuvieran una presencia continuada en el mercado de trabajo informal para obtener recursos, lo que aumentaría las posibilidades de deserción escolar de estos niños (Carvalho y Fontes, 2012). 
El programa Bolsa Familia tiene una organización descentralizada. Los municipios identifican a los potenciales beneficiarios del programa, que son incluidos en la base de datos del registro unificado. Por otra parte, la selección efectiva de los beneficiarios se realiza mediante el banco público Caixa Econômica Federal, en base a criterios de ingresos y composición familiar. El control de las condiciones que fija el programa es una función de los municipios, hecho que facilita una economía de recursos pues las estructuras municipales existentes ayudan en la implementación del programa y no hay que crear una nueva organización para ello (Soares, 2011; Soares, Ribas y Soares, 2009). La gestión de recursos es responsabilidad de la Caixa Econômica Federal, que es la institución encargada de efectuar el pago de la prestación. Neves y Helal (2007) señalan a este factor como la principal causa del éxito del programa. Los autores afirman que el personal de la Caixa Econômica Federal es independiente de los intereses y grupos locales, lo que aumenta la capacidad de ejercer control sobre las acciones de los departamentos municipales. Frente al carácter clientelear de la sociedad brasileña arraigado desde la época colonial, la existencia de una institución burocrática que goza de autonomía permite que haya una separación entre los gestores y la sociedad, y que se reduzca el riesgo de una explotación indebida del programa orientada por los objetivos interesados de diferentes actores sociales y políticos. El hecho es que la intervención de la Caixa Econômica Federal es un arreglo institucional que produce un "aislamiento burocrático" que afecta directamente al programa Bolsa Familia (Soares, 2011; Neves y Helal, 2007). Tal aislamiento preserva al Estado de la presión de grupos de interés. Sin embargo, este factor puede socavar la aplicación de las políticas al obstaculizar la capacidad del Estado para conocer las demandas reales de la sociedad, lo que sería un resultado perverso. Ahora bien, este aspecto negativo no se observó en el caso del programa Bolsa Familia.

Otro elemento institucional del programa mencionado por Neves y Helal (2007) es el "isomorfismo organizativo", caracterizado como el proceso por el que una institución es obligada a emular y competir con otras instituciones. El isomorfismo puede ser coercitivo (presiones formales e informales), mimético (imitación de respuestas e incertidumbres) y normativo (profesionalización de los directores y especialistas). Con respecto al isomorfismo coercitivo, es una función de la Caixa Econômica Federal obligar a los municipios a que se ajusten a sus normas y patrones de operación. El isomorfismo mimético se observa también en el momento en que las instituciones tienen como modelo a la Caixa Econômica Federal. Por último, el isomorfismo normativo se observa en la profesionalización que la gestión del programa Bolsa Familia causa en las instituciones involucradas, especialmente en la administración municipal. Este arreglo institucional permite una adecuada focalización del programa, ya que pocas familias no elegibles están recibiendo el beneficio, y un alto nivel de eficiencia, porque gran parte de las familias elegibles reciben el Bolsa Familia. En definitiva, los recursos utilizados por el programa Bolsa Familia se destinan a aquellos que realmente necesitan la ayuda: 
las familias de bajos ingresos (Soares, 2011). En concreto, más del $80 \%$ de los recursos del programa se destinan a los $40 \%$ más pobres de la población (Castro y Modesto, 2010). Idealmente, todas las familias dentro del grupo objetivo del programa Bolsa Familia deberían recibir las prestaciones del mismo. Sin embargo, debido a restricciones de presupuesto, no es posible tener una cobertura más amplia (Barros, Carvalho, Franco y Mendonça, 2008).

El efecto del programa Bolsa Familia en la reducción inmediata de la pobreza y en la frecuencia de asistencia escolar de los niños se ha documentado en estudios anteriores. Soares (2011) indica que el Bolsa Familia fue el gran responsable de la reducción de la desigualdad ocurrida en el país en los últimos años. Las transferencias sociales focalizadas representaron una tercera parte de esta reducción. De este porcentaje, el $20 \%$ de la reducción de la desigualdad se debió al programa Bolsa Familia. Vaz (2012) analizó el impacto del Bolsa Familia sobre la desigualdad de ingresos en 2010. Se constataron asociaciones significativas entre el programa Bolsa Familia y la disminución de la desigualdad de ingresos entre las familias pobres y en extrema pobreza. La incidencia del programa en las familias más pobres representó una caída sistemática de la desigualdad de rentas (Vaz, 2012). Tavares (2008) señala que las mujeres atendidas por el programa tienden a disminuir sus horas de trabajo, tanto en relación con todas las mujeres, como en comparación con las mujeres del mismo rango de ingresos. Sin embargo, esta reducción no es significativa. Este resultado pone de manifiesto que el temor planteado inicialmente de que los beneficiarios no buscarían mejorar sus condiciones de vida, con el fin de continuar recibiendo la ayuda del programa, no resulta confirmado por los análisis empíricos. Otra dimensión analizada es la relación entre el Bolsa Familia y la fecundidad. Estos estudios se basan en la hipótesis de que los beneficiarios tendrían estímulo para tener más hijos, porque el montante del beneficio depende del número de hijos. Las conclusiones de estos estudios constatan que los beneficiarios del programa tienen en realidad menores tasas de fecundidad que los no beneficiarios (Rocha, 2010; Signorini y Queiroz, 2011).

Otros estudios también investigaron la asociación entre el programa Bolsa Familia y el sistema electoral brasileño. Algunas análisis muestran un impacto significativo entre los beneficiarios del programa en el voto a Lula en las elecciones de 2006, así como en evaluaciones positivas de la labor realizada por el presidente (Licio, Rennó y Castro, 2009). Se ha comprobado que Lula obtuvo porcentualmente más votos en los municipios que más recursos per cápita recibieron del Bolsa Familia (Nicolau y Peixoto, 2007). Así, realizando un análisis geográfico se observó que Lula obtuvo en 2006 más votos en municipios de menor desarrollo, al contrario de lo que ocurrió en 2002 (Shikida et al., 2009). Sin embargo, los resultados de estudios econométricos indican que el Bolsa Familia no tuvo un efecto estadísticamente significativo en las elecciones presidenciales. La magnitud del coeficiente que relaciona el voto con la prestación económica no fue lo suficientemente elevada como para hacer al programa responsable de 
la reelección de Lula. (Shikida et al., 2009). El Bolsa Familia fue un símbolo del compromiso de Lula con la mejora de las condiciones de vida de la población más pobre (Coimbra, 2007; Singer, 2009). Ahora bien, el éxito electoral de Lula se ha considerado resultante de múltiples factores como los cambios en el mercado de trabajo, la mejora en el poder de compra, la baja inflación, el aumento de las exportaciones, el incremento de los productos de consumo popular con precios más bajos, el aumento de los ingresos reales de los pobres brasileños así como de la reducción de la desigualdad (Coimbra, 2007; Shikida et al., 2009).

Amaral y Monteiro (2013) constataron que los niños que viven en hogares beneficiados por el programa Bolsa Familia presentaron menores probabilidades de abandono escolar en 2005 y 2009. Este resultado demuestra que las condiciones del programa en materia de educación están siendo seguidas por las familias beneficiarias. Carvalho y Fontes (2012) indican que los niños atendidos por el Bolsa Familia tuvieron mayor frecuencia de asistencia a la escuela y menor probabilidad de abandono escolar, en comparación con los niños no beneficiarios, pero esta diferencia no fue estadísticamente significativa, según los datos de la Pesquisa por Amostra de Domicílios de Minas Gerais (PAD-MG) de 2009.

Basándonos en estos estudios previos, en esta investigación se ponen a prueba una serie de hipótesis sobre las probabilidades de que los niños frecuenten la escuela. El análisis principal examinará si los niños que viven en hogares beneficiarios del Bolsa Familia tienen mayores probabilidades de estar escolarizados, en comparación con los niños no beneficiarios. Además, buscamos poner a prueba la hipótesis de que existe una mayor probabilidad de que el niño no frecuente la escuela cuando la madre tiene mayor edad, es de color negro o mestiza y tiene menor escolaridad. De acuerdo con la propuesta del programa Bolsa Familia de interferir en las condiciones familiares para mejorar las condiciones de vida entre generaciones, es preciso considerar la manera en que las variables relativas al capital social de la familia tienen impacto en la mejora de las condiciones educativas de los niños. En este sentido definimos el capital social como un conjunto de recursos actuales o potenciales que están vinculados a la posesión de una red duradera, más o menos institucionalizada, de inter-conocimiento y de inter-reconocimiento (Bourdieu, 1980). También entendemos el capital social como la capacidad de acción de una colectividad para maximizar la satisfacción del interés colectivo, superando las dificultades creadas por la acción individual egoísta (Neves et al., 2007).

La asociación entre capital social y educación engloba dimensiones tanto familiares como extra-familiares (Coleman, 1988). Se supone que el capital social de la familia permite el acceso del niño al capital humano de los adultos, lo que implica cambios en sus habilidades y capacidades así como la aparición de nuevas pautas de comportamiento. Por otra parte, el capital humano de la madre tendrá impacto en la formación de capital humano de los hijos sólo cuando ella tenga participación en la vida de los niños. 
Esta influencia depende de la presencia de la madre en el entorno familiar. También la inserción de la familia en las redes sociales y en el ámbito comunitario está asociada positivamente con la escolaridad. Finalmente el capital social es fundamental para el desarrollo económico, así que cuanto mayor sea el capital social del individuo, mayores serán sus probabilidades de tener mejores niveles educacionales (Putnam, 2000). En definitiva, el capital social familiar (representado por el tiempo de la madre en el ambiente doméstico) y el capital social comunitario (representado por las redes extrafamiliares y medido por un indicador de participación en organizaciones sociales) presentan un impacto positivo en el desarrollo educativo de los hijos (Neves et al., 2007).

Por todo ello en la construcción del modelo explicativo, primero, se determinan las variables independientes que intentan medir la asociación entre indicadores de capital social de la familia y de la madre con la frecuencia de asistencia escolar de los niños. Por ejemplo, se pondrá a prueba la hipótesis de que el número de horas trabajadas por semana por la madre tiene una asociación negativa con esta frecuencia. Asimismo la información del tiempo de residencia en el municipio buscará poner a prueba la hipótesis de que la reciente migración de la madre disminuiría la probabilidad de que los niños estén escolarizados. Se comprobará también si los niños que viven en hogares encabezados por las madres tienen menores probabilidades de asistir a la escuela. Posteriormente, se presenta la estrategia de investigación de este estudio, teniendo en cuenta las bases de datos, variables, hipótesis y modelos de regresión.

\section{Diseño de investigación}

En este estudio se ha utilizado la base de datos del Censo Demográfico de 2010, elaborado por el Instituto Brasileño de Geografía y Estadística (IBGE). En todo el país se han seleccionado 6.192.332 hogares para responder al cuestionario detallado, lo que significa una fracción de muestreo efectiva del orden de 10,7\% para el país. En estos hogares, se han evaluado informaciones de todos los moradores, lo que totalizó 20.635.472 personas. Se han aplicado cinco fracciones de muestreo en la obtención de los datos, teniendo en cuenta el tamaño de los municipios, en base a la población estimada en el día 1 de julio de 2009. En la definición de la fracción de muestreo para los municipios pequeños se ha tratado de garantizar un tamaño suficiente para la extrapolación de resultados. Para los 40 municipios con más de 500.000 habitantes, se ha evaluado la posibilidad de aplicar diferentes fracciones de muestreo en cada una de sus divisiones administrativas intra-municipales (distritos y sub-distritos), permitiendo estimaciones en estos niveles geográficos (IBGE, 2013).

Para el presente estudio, se han analizado los niños con edad entre 7 y 14 años que viven en hogares beneficiarios y no beneficiarios del programa Bolsa Familia. Este grupo de edad es el que contempla el programa para exigir la escolarización de los niños 
beneficiarios. Se realizaron estimaciones para tres rangos de ingreso per cápita del hogar. La primera banda contiene los niños que viven en hogares con un ingreso per cápita de hasta 70,00 Reales. Este límite tiene como objetivo comprender la situación de los niños en hogares con situaciones económicas más precarias. El segundo rango incluye a los niños en hogares con ingresos per cápita de hasta 140,00 Reales, que es la cuantía límite oficial de elegibilidad para recibir las prestaciones del programa Bolsa Familia en 2010. El tercer rango contiene aquellos con ingresos familiares per cápita de hasta 280,00 Reales. Este límite permite aumentar el tamaño de la muestra analizada y comprobar el efecto de la recepción de las ayudas del programa sobre la asistencia escolar de los niños en hogares con mejores ingresos. En consecuencia, se pueden comparar las personas en situaciones económicas y de vulnerabilidad social similares, y con ello aumentar la validez y fiabilidad de las inferencias.

El objetivo principal de este trabajo es investigar si los niños entre 7 y 14 años, residentes en hogares beneficiarios del Programa Bolsa Familia, tienen mayores probabilidades de frecuencia de asistencia a la escuela, en comparación con niños no beneficiarios. Esta investigación tiene un diseño no experimental, ya que la selección de los beneficiarios de la política no se realizó de manera aleatoria. Por lo tanto, es preciso realizar un análisis multivariable para investigar el efecto de la política pública (programa Bolsa Familia) sobre la variable de interés (frecuencia de asistencia a la escuela), en que se lleva a cabo un control de los efectos de otras variables explicativas. Inicialmente, se realiza un análisis de la distribución de los niños por las categorías de las variables independientes (Cuadro 1). A continuación, se investiga el porcentaje de la variable dependiente (información sobre si el niño está escolarizado en 2010) por límites de ingresos per cápita del hogar y por la condición de ser receptor de las ayudas del programa Bolsa Familia. Los tests de diferencia de promedios permiten comprobar si los porcentajes de la variable dependiente presentan diferencias estadísticamente significativas al comparar los niños que recibieron y no recibieron las prestaciones del programa en cada banda del ingreso per cápita del hogar (Cuadro 2). Por último, estimamos modelos de regresión logística para explicar la frecuencia de asistencia escolar de los niños (Cuadro 3). Los errores estándar fueron ajustados según los clusters por municipio. Donde $Y$ es la variable dependiente dicotómica (los niños que frecuentan la escuela reciben valor igual a uno, mientras que los niños que no asisten a la escuela reciben el valor cero) y $X_{k}$ son las variables independientes; el modelo de regresión logística binaria se puede exponer de esta manera:

$$
\begin{aligned}
& \operatorname{Pr}(\mathrm{Y}=1 \mid \mathrm{B})=\mathrm{P} \\
& \log [\mathrm{P} /(1-\mathrm{P})]_{\mathrm{i}}=\beta_{0}+\beta_{\mathrm{k}} \mathrm{X}_{\mathrm{ki}}+\mathrm{u}_{\mathrm{i}} .
\end{aligned}
$$

En cuanto a las variables independientes, se han seleccionado las variables del hogar, de la madre, del niño y de la recepción del programa Bolsa Familia. Entre las variables de los hogares disponibles en el Censo Demográfico que pueden explicar la frecuencia 
de asistencia a la escuela, fueron seleccionadas: (1) número de miembros del hogar; (2) presencia de red de agua canalizada; (3) iluminación eléctrica; (4) recogida de basura; (5) localización del hogar (rural o urbana); y (6) región de residencia (Norte, Noreste, Sur, Sudeste y Centro-Oeste). Se han utilizado las siguientes variables referentes a la madre: (1) información de si la madre es la responsable del hogar; (2) la color/raza (negra/mestiza o blanca); (3) educación; (4) edad; (5) tiempo de residencia en el municipio; y (6) horas trabajadas por semana. En cuanto a las características del niño, se ha seleccionado: (1) edad; y (2) sexo. Es importante enfatizar que algunas variables que pueden estar asociadas con el aumento de la probabilidad de que el niño frecuente la escuela no fueron incluidas en el modelo analítico, como por ejemplo la motivación del niño para los estudios, porque no están disponibles en el banco de datos o porque no es posible medirlas. A continuación, detallamos la construcción de las variables utilizadas en los análisis, así como sus hipótesis específicas.

\subsection{Variables del hogar}

Número de miembros del hogar: se pregunta cuántos miembros residen en el hogar. Utilizamos esta variable de manera continua. Hipótesis: con el aumento del número de personas en el hogar, es menor la probabilidad de que el niño frecuente la escuela. Como los hogares estudiados tienen bajos ingresos per cápita, los hogares con varios miembros son un indicio de que los residentes tienen niveles socioeconómicos bajos, lo que reduce la posibilidad de que el niño frecuente la escuela.

Presencia de red de agua canalizada: se pregunta si hay red de abastecimiento de agua en casa, con tres respuestas posibles: (1) sí, en al menos una habitación; (2) sí, sólo en la propiedad o terreno; y (3) no. La variable fue recodificada en una variable binaria en la que se agregaron las dos primeras opciones de respuesta (valor uno), en comparación con la tercera opción (valor cero). Hipótesis: cuanto mejor sea la infraestructura del hogar, más propicio será el ambiente para que el niño se dedique a los estudios, lo que aumenta su oportunidad de frecuentar la escuela.

Iluminación eléctrica: se pregunta si hay electricidad en el hogar, con tres opciones de respuesta: (1) sí, de una empresa distribuidora; (2) sí, de otras fuentes; y (3) no hay iluminación eléctrica. La variable fue recodificada agregando las dos primeras categorías (valor uno), en comparación con la tercera categoría (valor cero). Hipótesis: cuanto mejor sea la infraestructura del hogar, más adecuado será el ambiente familiar para que el niño se dedique a los estudios, lo que aumenta su oportunidad de frecuentar la escuela.

Recogida de basura: se preguntó cómo se recoge la basura en el hogar, con siete opciones de respuesta: (1) directamente a través del servicio de limpieza; (2) colocado en cubo de servicio de limpieza; (3) quemado en la propiedad; (4) enterrado en la propiedad; (5) arrojado en un terreno baldío o en la calle; (6) arrojado al río, lago o mar; y 
(7) tiene otro destino. La variable fue recodificada para componer una variable binaria. Los que contestaron que los residuos son recogidos directamente por el servicio de limpieza o que se colocan en un cubo de servicio de limpieza fueron agrupados y se les asignó valor uno. Se le asignó el valor cero a los que respondieron las otras opciones. Hipótesis: cuanto mejor sea la infraestructura del hogar, más adecuado será el ambiente familiar para que el niño se dedique a los estudios, lo que aumenta su oportunidad de frecuentar la escuela.

Localización del hogar: de acuerdo con la ubicación del hogar, este fue clasificado por el Instituto Brasileño de Geografía y Estadística (IBGE) como rural o urbano. Se creó una variable dicotómica a la que se le asignó un valor de cero para los hogares situados en la zona rural y el valor uno para los hogares ubicados en la zona urbana. $\mathrm{Hi}$ pótesis: las áreas urbanas tienen mejor estructura de escuelas, relacionadas con mejores condiciones sociales y financieras de estas áreas. Por lo tanto, se supone que los niños que viven en zonas urbanas tienen mayores probabilidades de frecuentar la escuela que los niños que viven en zonas rurales.

Región de residencia: de acuerdo con el municipio de residencia, clasificamos la región geográfica de residencia. Se construyeron cinco variables dicotómicas para las regiones (Norte, Nordeste, Sudeste, Sur y Centro-Oeste). La región Sudeste es la referencia en el modelo de regresión. Hipótesis: existen diferencias de escolarización de los niños entre las regiones de Brasil que se deben a varios factores no observados como son la disponibilidad de las escuelas, el trabajo infantil y la empleabilidad de los padres. Como tales informaciones no se contemplan en el Censo Demográfico, las variables de región geográfica sirven de control para estas variaciones.

\subsection{Variables de la madre}

Para este bloque de variables se recogieron características de las madres de los niños. Posteriormente, estas variables de las madres fueron asignadas a sus respectivos hijos.

Madre responsable del hogar: se preguntó cuál era la relación de parentesco o convivencia con el responsable del hogar. Había veinte categorías de esta variable: (1) la persona responsable del hogar; (2) cónyuge o compañero(a) de sexo opuesto de la persona; (3) cónyuge o compañero(a) del mismo sexo; (4) hijo(a) del responsable y del cónyuge; (5) hijo(a) solamente del responsable; (6) hijastro(a); (7) yerno o nuera; (8) padre, madre, padrastro o madrastra; (9) suegro(a); (10) nieto(a); (11) biznieto(a); (12) hermano o hermana; (13) abuelo o abuela; (14) otra relación; (15) agregado; (16) conviviente; (17) pensionista; (18) empleado(a) doméstico(a); (19) pariente del empleado(a) doméstico(a); y (20) individual en hogar colectivo. Para las madres que eran la persona responsable del hogar se asignó valor igual a uno, mientras que para las que eran cónyuges o compañeras de sexo opuesto del responsable del hogar se asignó valor igual a cero. Hipótesis: la madre que es la responsable del hogar está más sobrecargada y el 
niño tiene menos apoyo para sus actividades escolares, especialmente si no hay presencia del padre para la división de las tareas y responsabilidades, lo que puede reflejarse en los indicadores educacionales.

Color/raza: se preguntó el color/raza del encuestado, que se clasificó como: (1) blanca; (2) negra; (3) amarilla; (4) mestiza (marrón); o (5) indígena. Los niños de las madres de color amarillo o indígenas fueron eliminados de la base de datos, ya que tienen pequeños porcentajes en Brasil y su inclusión podría generar problemas de heterocedasticidad en los modelos. Por otra parte, se recodificó la información de color/raza para construir una variable binaria que determina si la madre es de color/raza negra/ mestiza o blanca. El valor uno indica que la madre era blanca. Se asociaron las otras categorías (negra y mestiza) al valor cero. Hipótesis: los niños con madres de color/ raza blanca tienen mayores probabilidades de frecuentar la escuela que los hijos de madres negras/mestizas. Eso se debe a las desigualdades raciales en relación a indicadores sociales y económicos.

Escolaridad: el punto contemplado en este bloque fue la educación de la madre. Se preguntó cuál era su nivel de educación, con cinco categorías disponibles: (1) sin enseñanza o primaria incompleta; (2) primaria completa o secundaria incompleta; (3) secundaria completa o superior incompleto; (4) nivel superior completo; y (5) no determinada. Se crearon variables dicotómicas para cada una de las categorías, con la excepción de la quinta (no determinada), que fue excluida de la base de datos. Para los modelos de regresión, se optó por utilizar la categoría sin enseñanza o primaria incompleta como la referencia de la categoría. Hipótesis: la madre que tiene un mayor nivel de escolaridad puede colaborar con mayor eficacia en las actividades del niño en la escuela, lo que aumenta las probabilidades de que los niños frecuenten las clases.

Edad: se construyeron cuatro variables dicotómicas para la edad: (1) madres de hasta 24 años; (2) madres entre 25 y 34 años; (3) madres entre 35 y 49 años; y (4) madres de 50 años o más. La segunda categoría fue elegida como referencia para el análisis. Hipótesis: los niños con madres en edades intermedias (25 y 34) tienen mayores probabilidades de frecuentar la escuela. Las madres más jóvenes (hasta 24 años) tendrían menor poder persuasivo sobre sus hijos, lo que reduce la frecuencia escolar de estos niños. Del mismo modo, las madres con mayor edad (35 años o más) tendrían menor motivación para comprometer su tiempo en estimular a sus hijos a frecuentar la escuela.

Tiempo de residencia en el municipio: se preguntó cuánto tiempo hacía que la familia vivía en el municipio, lo que permitió la categorización de las madres en: (1) las que vivían de 0 a 4 años en el municipio; (2) las que vivían de 5 a 9 años; y (3) las que vivían desde hacía 10 años o más en el municipio. Esta última categoría fue la referencia en el modelo estadístico. Hipótesis: los hijos de madres que residen hace poco tiempo en el municipio tendrían menores probabilidades de estar escolarizados, debido a la falta de integración de las madres en el nuevo entorno residencial. Las madres que son 
inmigrantes recientes no están suficientemente familiarizadas con el lugar de residencia y no conocen las oportunidades para la escolarización de sus hijos.

Horas trabajadas por semana: se preguntó cuántas horas por semana destinaban las personas al trabajo principal. Luego se construyeron cuatro variables binarias con esta información: (1) las madres que no trabajaban; (2) las madres que trabajaban de 1 a 20 horas por semana; (3) las madres que trabajaban de 21 a 39 horas por semana; y (4) las madres que trabajaban más de 40 horas por semana. La primera categoría fue utilizada como referencia en los modelos logísticos. Hipótesis: las madres que trabajan más horas por semana están más sobrecargadas y el niño tiene menos apoyo para sus actividades escolares, especialmente si el padre no está presente para una división de las tareas y responsabilidades, lo que puede reflejarse en los indicadores educacionales.

\subsection{Variables del niño}

Edad: la edad del niño (7 a 14 años) se utiliza continuamente en los modelos. Hipótesis: cuanto mayor sea la edad del niño, menor será la probabilidad de que esté escolarizado. Esto sucede por la entrada de los niños en el mercado laboral, así como por la creación de familias de padres adolescentes.

Sexo: se construyó una variable binaria en la que los niños recibieron valor igual a uno y niñas recibieron valor igual a cero. Hipótesis: los niños varones tienen menores posibilidades de frecuentar la escuela, debido a su rápida entrada en el mercado de trabajo, en comparación con las mujeres.

\subsection{Variable de la política pública}

Beneficiario del programa Bolsa Familia: se construyó una variable dicotómica, donde los niños residentes en hogares beneficiarios del programa Bolsa Familia tienen valor igual a uno y los no beneficiarios tienen valor cero. Hipótesis: los niños beneficiarios están sometidos a la condición de recibir educación, lo que aumenta sus probabilidades de estar escolarizados. Por otra parte, estos niños no tendrían que ayudar en el complemento de los ingresos del hogar, precisamente debido al efecto del beneficio financiero del programa Bolsa Familia, lo que aumenta el tiempo disponible para el estudio y las probabilidades de frecuentar la escuela.

\section{Resultados}

La muestra final utilizada en este análisis consiste en un total de 1.675 .797 niños entre 7 y 14 años que viven en hogares con un ingreso per cápita de no más de 280,00 Reales. De ellos, 911.272 niños viven en hogares con ingresos per cápita de hasta 140,00 Reales y 
447.046 viven en hogares con un ingreso per cápita de 70,00 Reales. El Cuadro 1 muestra la distribución porcentual de los niños en las distintas categorías de las variables independientes para los tres límites de ingreso per cápita del hogar. El número de miembros del hogar fue de cinco a seis en los tres límites de ingresos analizados. El porcentaje de niños que viven en hogares con presencia de red de agua canalizada, iluminación eléctrica y con recogida de basura se incrementó con el aumento de los límites del ingreso per cápita del hogar. Se observa que el $71,54 \%$ de los niños viven en hogares con presencia de red de agua canalizada corriente en el límite de 70,00 Reales de renta per cápita del hogar, aumentando hasta el 84,89\% en el límite de ingresos de hasta 280,00 Reales. En la variable de la iluminación eléctrica, estos valores fueron de $92,27 \%$ a 96,65\%. Mientras que en la variable de la existencia de un servicio de recogida de basura fue de 54,08\% y $71,98 \%$ en los mismo límites de renta. En todos los grupos de ingresos, la mayor fracción de los niños reside en hogares ubicados en zonas urbanas. Con respecto a las zonas de residencia, se observa que la mayoría de los niños residen en la región Nordeste $(42,66 \%)$ para los hogares con ingreso per cápita de hasta 280,00 Reales. Para los niños que viven en hogares con una renta per cápita de hasta 140,00 Reales, el 51,04\% estaban situados en el Noreste. En el límite inferior de ingresos, el 54,35\% de los niños residen en el Noreste.

CuAdro 1: Distribución PORCENTUAL DE LOS NIÑOS POR CATEGORÍAS DE VARIABLES DE INTERÉS, BRASIL, 2010

\begin{tabular}{|c|c|c|c|c|}
\hline \multirow[t]{2}{*}{ Variables } & \multirow[t]{2}{*}{ Categorías } & \multicolumn{3}{|c|}{$\begin{array}{l}\text { Límite máximo de } \\
\text { renta per cápita del hogar }\end{array}$} \\
\hline & & $\mathrm{R} \$ 70,00$ & $\mathrm{R} \$ 140,00$ & $\mathrm{R} \$ 280,00$ \\
\hline \multicolumn{5}{|l|}{ Variables del hogar } \\
\hline Número de miembros del hogar & Promedio & 5,73 & 5,78 & 5,43 \\
\hline \multirow{2}{*}{ Presencia de red de agua canalizada } & Sí & 71,54 & 77,78 & 84,89 \\
\hline & No & 28,46 & 22,22 & 15,11 \\
\hline \multirow{2}{*}{ Iluminación eléctrica } & Sí & 92,27 & 94,62 & 96,65 \\
\hline & No & 7,73 & 5,38 & 3,35 \\
\hline \multirow{2}{*}{ Basura recogida } & Sí & 54,08 & 61,64 & 71,98 \\
\hline & No & 45,92 & 38,36 & 28,02 \\
\hline \multirow{2}{*}{ Localización del hogar } & Rural & 44,54 & 37,68 & 28,32 \\
\hline & Urbana & 55,46 & 62,32 & 71,68 \\
\hline \multirow{5}{*}{ Región de residencia } & Norte & 16,89 & 15,52 & 13,30 \\
\hline & Nordeste & 54,35 & 51,04 & 42,66 \\
\hline & Sudeste & 20,10 & 22,87 & 29,54 \\
\hline & Sur & 4,91 & 6,20 & 8,66 \\
\hline & Centro-Oeste & 3,76 & 4,37 & 5,85 \\
\hline
\end{tabular}




\begin{tabular}{|c|c|c|c|c|}
\hline \multirow[t]{2}{*}{ Variables } & \multirow[t]{2}{*}{ Categorías } & \multicolumn{3}{|c|}{$\begin{array}{l}\text { Límite máximo de } \\
\text { renta per cápita del hogar }\end{array}$} \\
\hline & & $\mathrm{R} \$ 70,00$ & $\mathrm{R} \$ 140,00$ & $\mathrm{R} \$ 280,00$ \\
\hline \multicolumn{5}{|l|}{ Variables de la madre } \\
\hline \multirow{2}{*}{ Madre responsable por el hogar } & $\mathrm{Si}$ & 43,60 & 42,83 & 43,10 \\
\hline & No & 56,40 & 57,17 & 56,90 \\
\hline \multirow{2}{*}{ Color/raza } & Negra o mestiza & 74,18 & 73,41 & 69,43 \\
\hline & Blanca & 25,82 & 26,59 & 30,57 \\
\hline \multirow{4}{*}{ Escolaridad } & $\begin{array}{l}\text { Sin enseñanza o } \\
\text { primaria incompleta }\end{array}$ & 80,08 & 78,74 & 71,97 \\
\hline & $\begin{array}{l}\text { Primaria completa o } \\
\text { secundaria incompleta }\end{array}$ & 11,32 & 12,53 & 15,16 \\
\hline & $\begin{array}{l}\text { Secundaria completa o } \\
\text { superior incompleto }\end{array}$ & 7,56 & 8,00 & 11,93 \\
\hline & Superior completo & 1,03 & 0,73 & 0,94 \\
\hline \multirow{4}{*}{ Edad } & Hasta 24 años & 3,93 & 3,64 & 3,41 \\
\hline & 25-34 años & 40,12 & 40,11 & 38,49 \\
\hline & 35-49 años & 43,04 & 41,83 & 40,91 \\
\hline & 50 años o más & 12,91 & 14,43 & 17,19 \\
\hline \multirow{3}{*}{ Tiempo de residencia en el municipio } & 0-4 años & 7,47 & 8,23 & 8,86 \\
\hline & 5-9 años & 3,88 & 3,55 & 3,17 \\
\hline & 10 años o más & 87,25 & 88,23 & 89,36 \\
\hline \multirow{4}{*}{ Horas trabajadas por semana } & Ninguna & 74,27 & 68,49 & 60,07 \\
\hline & $1-20$ horas & 10,22 & 11,16 & 11,31 \\
\hline & 21-39 horas & 5,14 & 6,11 & 7,11 \\
\hline & 40 horas o más & 10,37 & 14,24 & 21,51 \\
\hline \multicolumn{5}{|l|}{ Variables del niño } \\
\hline Edad (7-14 años) & Promedio & 10,49 & 10,52 & 10,56 \\
\hline \multirow{2}{*}{ Sexo } & Femenino & 48,88 & 49,10 & 49,20 \\
\hline & Masculino & 51,12 & 50,90 & 50,80 \\
\hline \multicolumn{5}{|l|}{ Variables de la política pública } \\
\hline Beneficiario del & Sí & 37,37 & 37,00 & 32,08 \\
\hline Programa Bolsa Familia & No & 62,63 & 63,00 & 67,92 \\
\hline Tamaño de la muestra (n) & & 447.046 & 911.272 & 1.675 .797 \\
\hline
\end{tabular}

Fuente: Censo Demográfico del Brasil de 2010. 
Para los tres límites de ingresos, hay un equilibrio de los niños que viven en hogares en que las madres son las responsables, alrededor del 43\%. La mayoría de los niños son hijos de madres negras o mestizas, con el porcentaje más alto $(74,18 \%)$ observado en el límite inferior de renta. Del mismo modo, la mayoría de los niños tienen madres sin enseñanza o con escolaridad primaria incompleta $(80,08 \%$ en el límite de ingresos de 70,00 Reales per cápita del hogar; 78,74\% en el límite de 140,00 Reales; y 71,97\% en el límite de 280,00 Reales).

La mayoría de los niños tienen madres de edades comprendidas entre 35 y 49 años para los tres límites de renta: $43,04 \%$ en el límite de 70,00 Reales; $41,83 \%$ en el límite de 140,00 Reales; y 40,91\% en el límite de 280,00 Reales. Independientemente del límite de los ingresos, la mayoría de los niños son hijos de mujeres que llevan residiendo 10 años o más en el municipio. En cuanto a las horas trabajadas por semana por la madre, la mayoría de los niños tienen madres que no trabajaban en todos los límites de renta: 74,27\% (hasta 70,00 Reales); 68,49\% (hasta 140,00 Reales); y 60,07\% (hasta 280,00 Reales).

En cuanto a las características de los niños, no hay ninguna diferencia entre la edad promedio en los tres límites de renta analizados, que fue de aproximadamente 11 años. En cuanto al sexo, la mayoría son niños, algo más del $50 \%$ en todos los límites de renta per cápita del hogar. Con respecto a la recepción del programa Bolsa Familia, el $37,37 \%$ de los niños residen en hogares que reciben la prestación del programa, en el límite de renta per cápita de 70,00 Reales. Cuando el límite de renta aumenta hasta los 140,00 Reales, el porcentaje de niños beneficiarios se reduce al 37,00\%. En el límite de renta de 280,00 Reales, el porcentaje de niños que viven en hogares beneficiarios del programa se reduce al $32,08 \%$.

Cuadro 2: Porcentaje de niños Que estaban en la escuela por Ser beneficiarios del PROGRAMA Bolsa FAMILIA EN 2010.

Beneficiario del Programa

Límite máximo de renta per cápita del hogar

Bolsa Familia

$\mathrm{R} \$ 70,00$

$\mathrm{R} \$ 140,00$

$\mathrm{R} \$ 280,00$

Sí (tratamiento)

98,45

98,51

98,59

No (control)

95,78

96,44

96,99

Diferencia (tratamiento menos control)

$2,67 * * *$

$2,07 * * *$

$1,60 * * *$

Notas:

***Test de diferencia de promedios significativo al nivel de confianza de $99 \%$;

**Test de diferencia de promedios significativo al nivel de confianza de $95 \%$;

*Test de diferencia de promedios significativo al nivel de confianza de $90 \%$.

Fuente: Censo Demográfico del Brasil de 2010. 
Para el análisis de los niveles preliminares de la variable dependiente (el niño frecuenta la escuela), se ha elaborado el Cuadro 2, que muestra el porcentaje de niños que estaban en la escuela por ser receptores de las prestaciones del programa Bolsa Familia y por los límites de renta per cápita del hogar. El porcentaje de niños escolarizados aumenta ligeramente con el aumento del límite de renta per cápita del hogar. Los niños que viven en hogares beneficiados por el programa Bolsa Familia tienen mayores porcentajes de frecuencia de asistencia a la escuela, en comparación con los niños que viven en hogares que no se benefician del programa, en los tres límites de renta. La diferencia fue mayor (2,67\%) para el límite del grupo de ingreso familiar per cápita de hasta 70,00 Reales. Las diferencias entre hogares beneficiados y no beneficiados por el Programa Bolsa Familia fueron estadísticamente significativas en todos los límites de ingresos.

El Cuadro 3 muestra los "odds ratios" y los errores estándar robustos con significación estadística de las variables independientes de los modelos logísticos que explican la escolarización de los niños en cada límite de ingreso per cápita del hogar. Con respecto al modelo que agrega a los niños que viven en hogares con un límite de renta per cápita de hasta 70,00 Reales, se observa que el aumento de un residente en el hogar disminuye en un $6,70 \%\left[(0,933-1)^{*} 100\right]$ la probabilidad de que el niño esté en la escuela, manteniendo constantes las demás variables independientes. Residir en un hogar que tiene red de agua canalizada aumenta un 17,20\% la probabilidad de que el niño esté escolarizado. El efecto sobre la frecuencia de asistencia a la escuela es del $81,90 \%$ para los niños que viven en hogares con iluminación eléctrica. Vivir en hogares con recogida de basura no es estadísticamente significativo. Vivir en áreas urbanas disminuye la probabilidad de que el niño esté en la escuela en un 22,90\%, en comparación con los niños que viven en zonas rurales. Este resultado ha sido inesperado en relación con la hipótesis inicial de investigación. Los niños residentes en el Noreste tienen el $37,10 \%$ más de probabilidades de frecuentar la escuela, en comparación con los niños en el Sudeste. Los que viven en la región Sur tienen el 30,30\% más de probabilidades de frecuentar la escuela, en comparación con la categoría de referencia. Los residentes en el Norte tienen el 8,6\% menos de probabilidades de frecuentar la escuela, en comparación con los residentes en el Sudeste. 


\section{CUADRO 3: ODDS RATIOS Y EXPONENCIALES DE LOS ERRORES ESTÁNDARES ROBUSTOS ESTIMADOS POR MODELOS DE REGRESIÓN LOGÍSTICA PARA LA VARIABLE DEPENDIENTE “NIÑO ESTA- BA EN LA ESCUELA", BRASIL, 2010.}

\begin{tabular}{|c|c|c|c|}
\hline \multirow{2}{*}{ Variables independientes } & \multicolumn{3}{|c|}{ Límite de renta per cápita del hogar } \\
\hline & $(\mathrm{R} \$ 70,00)$ & $(\mathrm{R} \$ 140,00)$ & $(\mathrm{R} \$ 280,00)$ \\
\hline \multicolumn{4}{|l|}{ Variables del hogar } \\
\hline \multirow[t]{2}{*}{ Número de miembros del hogar } & $0,933 * * *$ & $0,934 * * *$ & $0,928 * * *$ \\
\hline & $(0,0041)$ & $(0,0032)$ & $(0,0025)$ \\
\hline \multirow[t]{2}{*}{ Presencia de red de agua canalizada } & $1,172 * * *$ & $1,245 * * *$ & $1,249 * * *$ \\
\hline & $(0,0330)$ & $(0,0272)$ & $(0,0229)$ \\
\hline \multirow[t]{2}{*}{ Iluminación eléctrica } & $1,819 * * *$ & $1,848 * * *$ & $1,803 * * *$ \\
\hline & $(0,0620)$ & $(0,0521)$ & $(0,0450)$ \\
\hline \multirow[t]{2}{*}{ Basura recogida } & 0,998 & 1,027 & $1,146^{* * *}$ \\
\hline & $(0,0370)$ & $(0,0274)$ & $(0,0243)$ \\
\hline \multicolumn{4}{|l|}{ Localización del hogar } \\
\hline Rural & referencia & referencia & referencia \\
\hline \multirow[t]{2}{*}{ Urbana } & $0,771 * * *$ & $0,775^{* * *}$ & $0,808 * * *$ \\
\hline & $(0,0279)$ & $(0,0203)$ & $(0,0167)$ \\
\hline \multicolumn{4}{|l|}{ Región de residencia } \\
\hline \multirow[t]{2}{*}{ Norte } & $0,914 * *$ & $0,874 * * *$ & $0,850 * * *$ \\
\hline & $(0,0337)$ & $(0,0238)$ & $(0,0178)$ \\
\hline \multirow[t]{2}{*}{ Nordeste } & $1,371 * * *$ & $1,238 * * *$ & $1,132 * * *$ \\
\hline & $(0,0445)$ & $(0,0283)$ & $(0,0191)$ \\
\hline Sudeste & referencia & referencia & referencia \\
\hline \multirow[t]{2}{*}{ Sur } & $1,303 * * *$ & $1,276^{* * *}$ & $1,221 * * *$ \\
\hline & $(0,0718)$ & $(0,0488)$ & $(0,0313)$ \\
\hline \multirow[t]{2}{*}{ Centro-Oeste } & 1,037 & 1,045 & 1,032 \\
\hline & $(0,0636)$ & $(0,0464)$ & $(0,0316)$ \\
\hline \multicolumn{4}{|l|}{ Variables de la madre } \\
\hline \multirow[t]{2}{*}{ Madre responsable del hogar } & $0,907 * * *$ & $0,838^{* * *}$ & $0,821 * * *$ \\
\hline & $(0,0216)$ & $(0,0147)$ & $(0,0109)$ \\
\hline \multicolumn{4}{|l|}{ Color/raza } \\
\hline Negra o mestiza & referencia & referencia & referencia \\
\hline \multirow[t]{2}{*}{ Blanca } & 0,979 & 1,004 & $1,035^{* *}$ \\
\hline & $(0,0266)$ & $(0,0200)$ & $(0,0154)$ \\
\hline \multicolumn{4}{|l|}{ Escolaridad } \\
\hline Sin enseñanza o primaria incompleta & referencia & referencia & referencia \\
\hline \multirow[t]{2}{*}{ Primaria completa o secundaria incompleta } & $1,271 * * *$ & $1,316^{* * *}$ & $1,427 * * *$ \\
\hline & $(0,0520)$ & $(0,0395)$ & $(0,0313)$ \\
\hline \multirow[t]{2}{*}{ Secundaria completa o superior incompleto } & $1,522 * * *$ & $1,663 * * *$ & $1,840 * * *$ \\
\hline & $(0,0853)$ & $(0,0700)$ & $(0,0528)$ \\
\hline
\end{tabular}




\begin{tabular}{|c|c|c|c|}
\hline \multirow{2}{*}{ Variables independientes } & \multicolumn{3}{|c|}{ Límite de renta per cápita del hogar } \\
\hline & $(\mathrm{R} \$ 70,00)$ & $(\mathrm{R} \$ 140,00)$ & $(\mathrm{R} \$ 280,00)$ \\
\hline \multirow[t]{2}{*}{ Superior completo } & $1,403^{* *}$ & $1,408 * * *$ & $1,613 * * *$ \\
\hline & $(0,207)$ & $(0,186)$ & $(0,150)$ \\
\hline \multicolumn{4}{|l|}{ Edad } \\
\hline \multirow[t]{2}{*}{ Hasta 24 años } & $0,191 * * *$ & $0,197 * * *$ & $0,187 * * *$ \\
\hline & $(0,0078)$ & $(0,0062)$ & $(0,0046)$ \\
\hline 25-34 años & referencia & referencia & referencia \\
\hline \multirow[t]{2}{*}{ 35-49 años } & $0,746^{* * *}$ & $0,768^{* * *}$ & $0,761 * * *$ \\
\hline & $(0,0210)$ & $(0,0161)$ & $(0,0126)$ \\
\hline \multirow[t]{2}{*}{50 años o más } & $0,503 * * *$ & $0,549 * * *$ & $0,592 * * *$ \\
\hline & $(0,0185)$ & $(0,0144)$ & $(0,0117)$ \\
\hline \multicolumn{4}{|l|}{ Tiempo de residencia en el municipio } \\
\hline \multirow[t]{2}{*}{ 0-4 años } & $0,711 * * *$ & $0,704 * * *$ & $0,691 * * *$ \\
\hline & $(0,0262)$ & $(0,0186)$ & $(0,0136)$ \\
\hline \multirow[t]{2}{*}{ 5-9 años } & $1,439 * * *$ & $1,451 * * *$ & $1,257 * * *$ \\
\hline & $(0,109)$ & $(0,0764)$ & $(0,0475)$ \\
\hline 10 años o más & referencia & referencia & referencia \\
\hline \multicolumn{4}{|l|}{ Horas trabajadas por semana } \\
\hline Ninguna & referencia & referencia & referencia \\
\hline \multirow[t]{2}{*}{ 1-20 horas } & $1,452 * * *$ & $1,399 * * *$ & $1,377^{* * *}$ \\
\hline & $(0,0594)$ & $(0,0412)$ & $(0,0308)$ \\
\hline \multirow[t]{2}{*}{ 21-39 horas } & $1,434 * * *$ & $1,419^{* * *}$ & $1,432 * * *$ \\
\hline & $(0,0786)$ & $(0,0545)$ & $(0,0402)$ \\
\hline \multirow[t]{2}{*}{40 horas o más } & $1,275^{* * *}$ & $1,169 * * *$ & $1,224 * * *$ \\
\hline & $(0,0476)$ & $(0,0284)$ & $(0,0207)$ \\
\hline \multicolumn{4}{|l|}{ Variables del niño } \\
\hline \multirow[t]{2}{*}{ Edad (7-14 años) } & $0,781 * * *$ & $0,774 * * *$ & $0,768 * * *$ \\
\hline & $(0,0046)$ & $(0,0034)$ & $(0,0027)$ \\
\hline \multicolumn{4}{|l|}{ Sexo } \\
\hline Femenino & referencia & referencia & referencia \\
\hline \multirow[t]{2}{*}{ Masculino } & $0,854 * * *$ & $0,820 * * *$ & $0,828 * * *$ \\
\hline & $(0,0193)$ & $(0,0137)$ & $(0,0106)$ \\
\hline \multicolumn{4}{|l|}{ Variable de la política pública } \\
\hline \multirow[t]{2}{*}{ Beneficiario del Programa Bolsa Familia } & $2,120^{* * *}$ & $1,961 * * *$ & $1,880 * * *$ \\
\hline & $(0,0569)$ & $(0,0384)$ & $(0,0294)$ \\
\hline Pseudo- $\mathrm{R}^{2}$ & 0,090 & 0,083 & 0,082 \\
\hline $\begin{array}{l}\text { Tamaño de la muestra (n) } \\
\text { Notas: } \\
\text { *** Significativo al nivel de confian } \\
\text { ** Significativo al nivel de confianz } \\
\text { * Significativo al nivel de confianza } \\
\text { estándar fueron ajustados según los } \\
\text { Fuente: Censo Demográfico }\end{array}$ & $\begin{array}{l}\text { ciales de los } \\
\text { ipio. }\end{array}$ & ar robustos en & Los errores \\
\hline
\end{tabular}


En cuanto a las características de la madre hay diversos resultados. Así un niño tiene un 9,3\% menos de probabilidades de estar escolarizado en el modelo de renta per cápita del hogar de hasta 70,00 Reales, cuando la madre es la responsable del hogar. La variable color/raza de la madre no tiene un efecto estadísticamente significativo sobre la probabilidad de frecuentar la escuela. Si la madre tiene escolaridad primaria completa o secundaria incompleta, hay un $27,10 \%$ más de probabilidades de que el niño esté escolarizado, en comparación con los hijos de madres sin enseñanza o con escolaridad primaria incompleta. Este porcentaje positivo es del 52,20\% entre los niños de madres con educación secundaria completa o nivel superior incompleto y del 40,30\% entre los niños de madres con nivel superior completo. En cuanto a la edad de la madre, los niños de madres de hasta 24 años tienen el $80,90 \%$ menos de probabilidades de estar escolarizados que los niños de madres de 25-34 años. Estos porcentajes negativos son del 25,40\% para los hijos de madres de 35-49 años, y del 49,70\% para los hijos de madres de 50 años o más. Estos resultados apoyan la hipótesis inicial de que los niños de madres más jóvenes o de mayor edad son más vulnerables y tienen menores probabilidades de estar escolarizados. Con respecto al tiempo de residencia, los niños con madres que residen 0-4 años en el municipio tienen un $28,90 \%$ menos de probabilidades de estar escolarizados en comparación con los niños cuyas madres llevan viviendo 10 años o más en el municipio. Los hijos de madres que residen 5-9 años en el municipio tienen el 43,90\% más de probabilidades de frecuentar la escuela, en comparación con la categoría de referencia. En relación a las horas trabajadas, los hijos de madres que trabajan 1-20 horas por semana tienen el 45,20\% más de probabilidades de estar escolarizados, en comparación con los hijos de madres que no trabajan. Tales porcentajes positivos son del $43,40 \%$ para los hijos de madres que trabajan 21-39 horas por semana, y del $27,50 \%$ para los hijos de madres que trabajan 40 horas o más por semana. Así, en hogares con una renta per cápita de hasta 70,00 Reales y con madres que trabajan, hay mayor posibilidad de que el niño esté escolarizado, en comparación con niños de madres que no tienen trabajo remunerado.

Con respecto a las variables de los niños, el aumento de un año de edad disminuye en un $21,90 \%$ la probabilidad de que el niño este escolarizado. Los niños varones presentan el 14,60\% menos de probabilidades de frecuentar la escuela, en comparación con las mujeres. Por último, los niños que viven en hogares beneficiados por el programa Bolsa Familia tienen un 112,00\% más de probabilidades de frecuentar la escuela, en relación con niños que viven en hogares no beneficiarios. Estas estimaciones presentan una mayor magnitud que en el análisis realizado por Amaral y Monteiro en 2013, lo que confirma la capacidad de la política de transferencias analizada para fomentar la escolarización de los niños.

En el modelo para los niños que viven en hogares con una renta per cápita de hasta 140,00 Reales, que es la cuantía límite oficial para ser elegible para la prestación en el programa Bolsa Familia en 2010, las variables tienen el mismo comportamiento de dirección de la asociación y significación estadística del modelo anterior. El aumento de 
un residente en el hogar disminuye la probabilidad de que el niño frecuente la escuela en un 6,60\%. Cuando el hogar en el que vive el niño hay agua canalizada, la probabilidad de que el niño esté escolarizado aumenta en un $24,50 \%$, en comparación con aquellos que no tienen red de agua canalizada. La existencia de iluminación eléctrica aumenta la probabilidad de que el niño esté escolarizado en un $84,80 \%$. Vivir en zonas urbanas reduce la probabilidad de que el niño frecuente la escuela en un $22,50 \%$, en comparación con niños que viven en la zona rural. Los niños que residen en el Nordeste tienen un $23,80 \%$ más de probabilidades de frecuentar la escuela, en comparación con los niños del Sudeste. Un niño del Sur tiene un 27,60\% más de probabilidades de frecuentar la escuela, en comparación con la categoría de referencia.

En relación a las variables de la madre cabe señalar que los niños que residen en hogares en que la madre es la responsable tienen el 16,20\% menos de probabilidades de estar escolarizados. La variable color/raza de la madre no es estadísticamente significativa. Los hijos de madres con escolaridad primaria completa o secundaria incompleta tienen el 31,60\% más de probabilidades de frecuentar la escuela, en comparación con los hijos de madres sin enseñanza o primaria incompleta. Estos porcentajes también son positivos para los niños de madres con escolaridad secundaria completa o nivel superior incompleto $(66,30 \%)$ y para los niños de madres con nivel superior completo $(40,80 \%)$. En cuanto a la edad de la madre, los hijos de madres de hasta 24 años tienen el $80,30 \%$ menos de probabilidades de estar escolarizados, en comparación con los niños de madres de 25-34 años. Estos porcentajes negativos son del 23,20\% para los niños de madres de $35-49$ años y del $45,10 \%$ para los hijos de madres de 50 años o más. Por lo que respecta al tiempo de residencia, los niños de madres que residen entre 0 y 4 años en el municipio tienen el 29,60\% menos de probabilidades de estar escolarizados, en comparación con los hijos de madres que llevan viviendo 10 años o más en el municipio. Cuando la madre lleva residiendo 5-9 años en el municipio, los niños tienen un $45,10 \%$ más de probabilidades de frecuentar la escuela, en comparación con la categoría de referencia. En relación al tiempo trabajado, los hijos de madres que trabajan 1-20 horas por semana tienen un 39,90\% más de probabilidades de estar escolarizados, en comparación con los hijos de madres que no trabajan. Estos porcentajes positivos son del $41,90 \%$ para los hijos de madres que trabajan 21-39 horas por semana y del 16,90\% para los hijos de madres que trabajan 40 horas o más por semana.

Respecto a las variables relacionadas con los niños se puede señalar que el aumento de un año en la edad disminuye en un $22,60 \%$ la probabilidad de que el niño esté escolarizado. Los niños del sexo masculino tienen un $18,00 \%$ menos de probabilidades de frecuentar la escuela que las niñas. Los niños que viven en hogares beneficiarios del programa Bolsa Familia tienen un 96,10\% más de probabilidades de frecuentar la escuela, en relación con niños que residen en hogares no beneficiarios. Aunque hay que precisar que esta asociación de la política de transferencia monetaria con la frecuencia escolar es inferior en el límite del renta per cápita del hogar de hasta 140,00 Reales que en el límite de hasta 70,00 Reales. 
En la investigación se realizó también una estimación del modelo para los niños que viven en hogares con una renta per cápita de hasta 280,00 Reales con el objetivo de garantizar la representatividad de la muestra en nuestras estimaciones. Con respecto a las variables del hogar, el hecho de aumentar un residente en el hogar disminuye en un 7,20\% la probabilidad de que el niño frecuente la escuela. Los niños que viven en hogares con red de agua canalizada tienen un $24,90 \%$ más de posibilidades de estar escolarizados. Los niños que viven en hogares con iluminación eléctrica tienen un $80,30 \%$ más de probabilidades de frecuentar la escuela. Los niños que viven en hogares con recogida de basura tienen un 14,6\% más de probabilidades de frecuentar la escuela. En cuanto a la localización del hogar, los niños que viven en zonas urbanas tienen un 19,2\% menos de probabilidades de frecuentar la escuela, en comparación con los niños que viven en las zonas rurales. Con respecto a la región de residencia, los niños que residen en el Nordeste tienen un 13,20\% más de probabilidades de estar en la escuela, en comparación con los que viven en el Sudeste. Los niños que residen en el Sur tienen un $22,10 \%$ más de probabilidades de estar escolarizados, en comparación con la categoría de referencia. En este modelo se observa un cambio en comparación con los anteriores. Para los estratos más bajos de ingreso per cápita del hogar, hubo una mayor asociación entre la percepción del programa Bolsa Familia y la frecuencia escolar en los niños que viven en el Nordeste. Tal vez esto se explica por la concentración de hogares beneficiarios del programa Bolsa Familia en el Nordeste, lo que aumentaría la probabilidad de que los niños estén escolarizados en esta región. Al aumentar el límite de renta per cápita del hogar, los niños se concentran en las regiones con mejores condiciones socioeconómicas y, en consecuencia, no están favorecidos por el programa.

Con respecto a las variables de la madre, los niños que viven en hogares en que las madres son las responsables del hogar tienen un $17,9 \%$ menos de probabilidades de estar escolarizados. Tal vez esto se debe a que estos hogares son los más vulnerables, cuando las madres no tienen la ayuda de un compañero. Los hijos de madres blancas tienen un 3,5\% más de probabilidades de estar escolarizados, en comparación con hijos de madres negras o mestizas. En cuanto a la escolaridad de las madres, los niños de madres con escolaridad primaria completa o secundaria incompleta tienen un $42,70 \%$ más de probabilidades de frecuentar la escuela, en comparación con los hijos de madres sin enseñanza o con primaria incompleta. Estos porcentajes positivos son del $84,00 \%$ para los niños de madres con secundaria completa o nivel superior incompleto y del $61,30 \%$ para los niños de madres con nivel superior completo. Para la variable "edad de la madre", los niños de madres de hasta 24 años tienen el 81,30\% menos de probabilidades de estar en la escuela, en comparación con los hijos de madres de 25-34 años. Estos porcentajes negativos son del 23,90\% para niños de madres de 35-49 años y del $40,80 \%$ para niños de madres de 50 años o más. En cuanto al tiempo de residencia, los niños de madres que residen $0-4$ años en el municipio tienen un 30,90\% menos de probabilidades de estar escolarizados, en comparación con los hijos de madres que 
vivieron 10 años o más en el municipio. Los hijos de madres que llevan viviendo 5-9 años en el municipio tienen el $25,70 \%$ más de probabilidades de estar en la escuela, en comparación con la categoría de referencia. Por lo que se refiere a las horas de trabajo, los niños de madres que trabajan de 1 a 20 horas por semana tienen el 37,70\% más de probabilidades de estar escolarizados, en comparación con los niños de madres que no trabajan. Estos porcentajes positivos son del $43,20 \%$ de los niños de madres que trabajan 21-39 horas por semana y del $22,40 \%$ para los niños de madres que trabajan 40 horas o más por semana.

Con respecto a las variables del niño, el aumento de un año de edad disminuye un $23,20 \%$ la probabilidad de que los niños estén escolarizados. Los niños de sexo masculino tienen un $17,20 \%$ menos de probabilidades de estar escolarizados que las niñas. Por último, los niños que viven en hogares beneficiarios del programa Bolsa Familia tienen el 88,00\% más de probabilidades de frecuentar la escuela, en comparación con los niños no beneficiarios. En todos los límites de renta per cápita del hogar, se observó que la condición de educación del programa Bolsa Familia parece ser importante para mantener a los niños en la escuela.

\section{Consideraciones finales}

A pesar de las dificultades de analizar el programa Bolsa Familia como una política educativa, porque esta opera sobre la demanda de educación y no sobre la calidad de la oferta, este trabajo ha realizado una comprobación de la capacidad que tiene la condición establecida en el programa de que las unidades familiares escolaricen a los niños a cambio de la prestación económica. Con base en los modelos de regresión logística estimados, en que se realiza el control de la variable dependiente por una serie de variables explicativas, se puede observar que la recepción de los beneficios del programa Bolsa Familia incrementa la probabilidad de la escolarización de los niños entre 7 y 14 años. Más específicamente, en el grupo de niños que viven en hogares con una renta per cápita de hasta 70,00 Reales, el programa aumentó en 112,00\% la probabilidad de que estos niños estén escolarizados. En el límite de ingreso per cápita del hogar de hasta 140,00 Reales, que corresponde a la condición de elegibilidad oficial para el programa, los niños que viven en hogares beneficiarios del programa Bolsa Familia tuvieron un $96,10 \%$ más de probabilidades de estar escolarizados, en comparación con los niños no beneficiarios. Finalmente, en el límite del ingreso per cápita del hogar de hasta 280,00 Reales, los niños beneficiarios del programa Bolsa Familia tienen un $88,00 \%$ más de probabilidades de estar escolarizados.

Estos resultados sugieren que la condición establecida de recibir educación para percibir el subsidio del programa Bolsa Familia ha sido importante para la escolarización de los niños. El propio beneficio económico ofrecido a los hogares por el programa 
disminuye la necesidad de que los niños entren en el mercado laboral para complementar los ingresos de los hogares, lo que hace aumentar la probabilidad de permanecer en la escuela. Estos resultados destacan la importancia de que el Gobierno conozca los niveles alcanzados en la escolarización de los niños beneficiarios del programa con el fin de aumentar las tasas de escolaridad de la población infantil y juvenil. El programa, por tanto, permite promover el aumento de las tasas de escolaridad de los niños y jóvenes a largo plazo, lo que puede ayudar a romper el ciclo intergeneracional de la pobreza. Además, como estos niños generalmente estudian en escuelas públicas, la investigación pone en evidencia que es importante invertir en la calidad de la educación pública del país.

Con respecto a las variables de capital humano familiar, en los resultados de la investigación se observa que una mayor presencia de la madre en el hogar, representada por 1 a 20 horas de trabajo por semana, se asocia positivamente con la frecuencia de la asistencia a la escuela de los niños en los tres límites de renta analizados. En estudios futuros se debe hacer un seguimiento de la escolarización de los niños y jóvenes beneficiarios del programa Bolsa Familia durante periodos más largos. La investigación pone de relieve también que es necesaria la elaboración y estudio de bases de datos que contengan información sobre el resultado del aprendizaje de las materias escolares por los niños, ya que el Censo Demográfico no tiene este tipo de variables. La investigación de los resultados del aprendizaje en pruebas de nivel nacional o local, así como la investigación de los indicadores de disparidad entre la edad y el grado educativo de los niños, beneficiarios y no beneficiarios del programa Bolsa Familia, será una manera de investigar más adelante el impacto social, económico y educativo que el programa tiene sobre tales individuos. Sería importante, además, contar con bases de datos que posean variables contextuales relacionadas con las escuelas para incluir en los modelos estadísticos.

\section{Bibliografía}

Amaral, E. F. L. y V. P. Monteiro (2013): “Avaliação de impacto das condicionalidades de educação do Programa Bolsa Família (2005 e 2009)", Revista Dados, 56 (3), pp. 531-570.

Barros, R. P. et al. (2006): "Uma Análise das Principais Causas da Queda Recente na Desigualdade de Renda Brasileira", Econômica, 8 (1), pp. 117-147.

Barros, R. P. et al. (2007): "Determinantes Imediatos da Queda da Desigualdade de Renda Brasileira”, Texto para Discussão n. 1253, Brasilia, Instituto de Pesquisa Econômica Aplicada (Ipea). 
BARRos, R. P. et al. (2008): “A Importância das Cotas para a Focalização do Programa Bolsa Família”, Texto para Discussão n. 1349, Brasilia, Instituto de Pesquisa Econômica Aplicada (Ipea).

Behrman, J. R., S. W. Parker y P. E. Todd (2005): "Long-term Impacts of the Oportunidades Conditional Cash Transfer Program on Rural Youth in Mexico", Discussion Paper $n$. 12, Ibero-American Institute for Economic Research.

Bourdieu, P. (1980): "Le Capital Social: Notes Provisoires", Actes de la Recherche en Sciences Sociales, 31, pp. 2-3.

Brasil (2012a): Cartão Alimentação, Brasília, Presidência da República Federativa do Brasil. (2012b). Bolsa Família, Brasília, Caixa Econômica Federal.

Campbell, D. y J. Stanley (1979): Delineamentos Experimentais e Quase-Experimentais de Pesquisa, São Paulo, EDUSP.

Carvalho, R. y M. Fontes (2012): “Avaliação do impacto do Programa Bolsa Família sobre indicadores de escolaridade em Minas Gerais", artículo presentado en el $15^{\circ}$ Seminário sobre a Economia Mineira, Diamantina/MG.

Castro, J. A. y L. Modesto (eds.) (2010): Bolsa Família 2003-2010: avanços e desafíosVolume. 2, Brasilia, Instituto de Pesquisa Econômica Aplicada (Ipea).

Cohen, E. y R. Franco (1993): Avaliação de projetos sociais, Petrópolis, Vozes, 2 ed.

Coimbra, M. (2007): "Quatro razões para a vitória de Lula", Cadernos Fórum Nacional, 6, pp. 5-13.

Coleman, J. (1988): "Social capital in the creation of human capital", American Journal of Sociology Supplement, 94, pp. 95-120.

Hoffmann, R. (2006): "Transferências de Renda e a Redução da Desigualdade no Brasil e Cinco Regiões entre 1997 e 2004", Econômica, 8 (1), pp. 55-81.

IBGE (2013): Notas metodológicas do Censo Demográfico do Brasil de 2010, Brasília, Instituto Brasileiro de Geografia e Estatística.

Janvry, A. de y E. SAdoulet (2005): "Conditional Cash Transfer Programs for Child Human Capital Development: Lessons Derived from Experience in Mexico and Brazil", GRADE 25th anniversary Conference, Banco Mundial, Lima.

Licio, E. C., L. R. Rennó y H. C. O. Castro (2009): "Bolsa Família e voto na eleição presidencial de 2006: em busca do elo perdido", Opinião Pública, 15 (1), pp. 31-54.

Neves, J. A. B. y D. H. Helal (2007): “Como pode ter dado certo? Insulamento Burocrático, inserção social e políticas públicas no Brasil: o caso do Programa Bolsa Família”, en Fahel, Murilo y Jorge A.B. Neves (eds.), Gestão e Avaliação de Políticas Sociais no Brasil, Belo Horizonte, PUC Minas, pp. 29-49. 
Neves, J. A. B. et al. (2007): "Políticas de Transferência Direta de Renda, Capital Social e Alcance Educacional no Brasil", en Fahel, Murilo y Jorge A.B. Neves (eds.), Gestão e Avaliação de Políticas Sociais no Brasil, Belo Horizonte, PUC Minas, pp. 275-290.

Nicolau, J. y V. Pеiхото (2007): “As bases municipais da votação de Lula em 2006", Cadernos Fórum Nacional, 6, pp. 15-25.

Oliveira, L. F. B. y S. S.D. SoAres (2013): "O impacto do programa bolsa família sobre a repetência: resultados a partir do cadastro único, projeto frequência e censo escolar", Texto para Discussão n. 1814, Brasília, Instituto de Pesquisa Econômica Aplicada (Ipea).

Putnam, R. D. (2000): Bowling alone: The collapse and revival of American community, New York, Simon \& Schuster.

Ravallion, M. y Q. Wodon (2000): "Does Child Labour Displace Schooling? Evidence on Behavioural Responses to an Enrollment Subsidy", Economic Journal, 110 (462), pp. C158-C175.

Rawlings, L. y G. Rubio (2005): "Evaluating the Impact of Conditional Cash Transfer Programs", The World Bank Research Observer, 20 (1), pp. 29-55.

Rios-Neto, E. L. G. (2010): "O Impacto do Programa Bolsa Família na Desigualdade de Renda”, artículo presentado en el $1^{\circ}$ Seminário Internacional de Gestão e Políticas Públicas, Belo Horizonte.

Rocha, R. (2010): Programas Condicionais de Transferência de Renda e Fecundidade: evidências do Bolsa-Família, Rio de Janeiro, PUC/Rio

Romero, J. A. R. (2008): Utilizando o relacionamento de bases de dados para avaliação de políticas públicas: uma aplicação para o Programa Bolsa Família, Tesis doctoral inédita, (CEDEPLAR), Universidade Federal de Minas Gerais (UFMG).

SAntanA, J. Á. (2007): “A evolução dos programas de transferência de renda e o Programa Bolsa Família”, Seminário População, Pobreza e Desigualdade, Belo Horizonte/MG.

SHIKIDA, C. D. et al. (2009): “'It is the economy, companheiro!': an empirical analysis of Lula's re-election based on municipal data", Economics Bulletin, 29 (2), pp. 1-14.

Signorini, B.. A. y B. L. Queiroz (2011): "The impact of Bolsa Família Program in the beneficiary fertility", Texto para Discussão n. 439, Belo Horizonte, UFMG/ CEDEPLAR.

Singer, A. (2009): "Raízes sociais e ideológicas do lulismo", Novos Estudos, 85, pp. 83102.

Skoufias, E. y S. W. Parker (2001): "Conditional Cash Transfers and Their Impact on Child Work and Schooling: Evidence from the PROGRESA Program in Mexico", Economía, 2 (1), pp. 45-96.

Skoufias, E. (2005): "Progresa and its Impacts on the Welfare of Rural Households in Mexico", Research Report 139, Washington, International Food Policy Research Institute (IFPRI). 
SoARes, F. V. et al. (2006): "Programas de Transferência de Renda no Brasil: Impactos sobre a Desigualdade. Brasília", Texto para Discussão n. 1228, Brasília, Instituto de Pesquisa Econômica Aplicada (Ipea).

SoAres, S. (2011): "O Programa Bolsa Família: desenho institucional e possibilidades futuras", Cadernos INESP, 2, pp. 145-184.

Soares, S., R. P. Ribas y F. V. Soares (2009): "Focalização e Cobertura do Programa BolsaFamília: qual o significado dos 11 milhões de famílias?”, Texto para Discussão n. 1396, Brasília, Instituto de Pesquisa Econômica Aplicada (Ipea).

VAz, A. C. N. (2012): "Efeitos do Programa Bolsa Família sobre a desigualdade e a extrema pobreza: análise e evidências a partir do Censo Demográfico 2010", Revista Brasileira de Monitoramento e Avaliação, 3, pp. 76-95. 